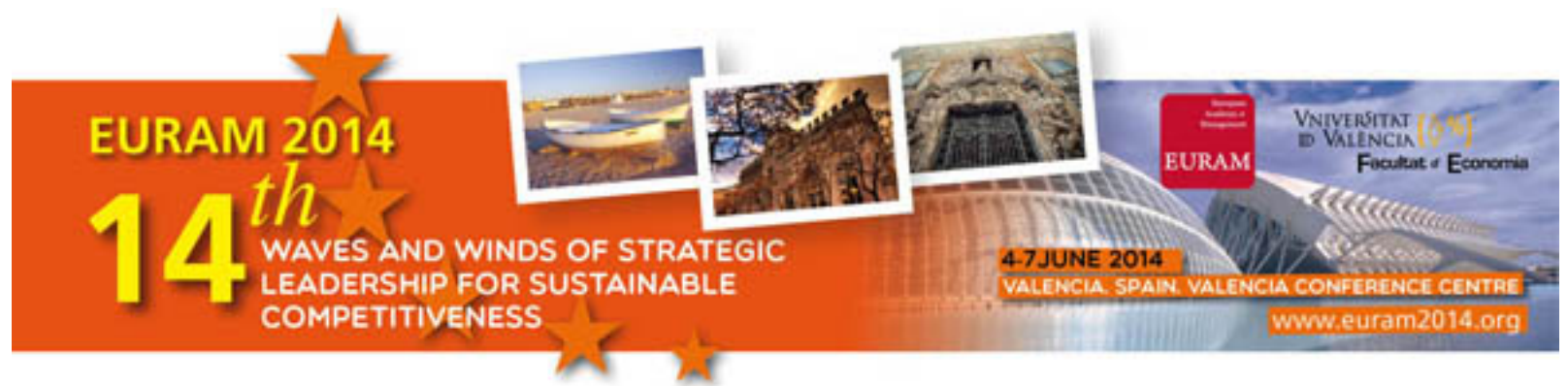

INVESTING IN VOLUNTEERING: MEASURING SOCIAL RETURNS OF PRIVATE INVESTM ENTS IN VOLUNTEER RECRUITMENT, TRAINING AND MANAGEM ENT ACTIVITIES

\author{
Marco Bellucci - marco.bellucci@ pin.unifi.it \\ UNIVERSITY OF FLORENCE \\ Elena Como - elena.como@ agenzialama.eu \\ LAMA AGENCY \\ Luca Bagnoli - luca.bagnoli@ unifi.it \\ UNIVERSITY OF FLORENCE \\ Giacomo Manetti - giacomo.manetti@ unifi.it \\ UNIVERSITY OF FLORENCE
}

Category: 12 PUBLC MANAGEM ENT \>12_00 PUBLIC M ANAGEMENT - GENERAL TRACK

Access to this paper is restricted to registered delegates of the EURAM 2014 (European Academy of M anagement) Conference.

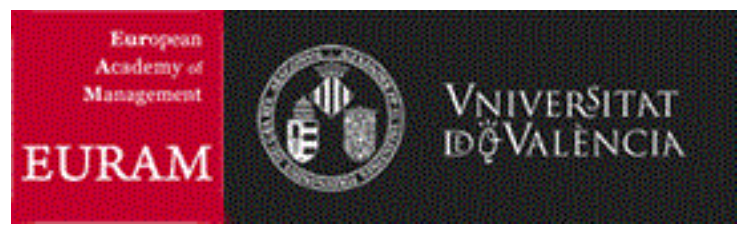

ISBN No: 978-84-697-0377-9. 


\title{
Investing in volunteering: measuring social returns of private investments in volunteer recruitment, training and management activities
}

\begin{abstract}
In this paper we analyze the costs and benefits of the investments that non-profit organizations (NPOs) make for the recruitment, training, and management of volunteers. Our main research question is whether we can apply the Social Return on Investment (SROI) to the identification and quantification of social returns in monetary terms. We believe that the "SROI of volunteering" may represent an effective instrument of internal control for NPOs for improving efficiency and sustainability. In order to verify the feasibility and appropriateness of the SROI approach, we present a case study on the Italian association Dynamo Camp, which works with children with serious illness through the organization of summer camps that offer "recreational therapy". We believe that the presented methodology has the potential to contribute to the debate about the socio-economic impact organizations create for volunteers and for society at large.
\end{abstract}

Keywords: Volunteering; SROI; Non-profit organizations 


\title{
Investing in volunteering: measuring social returns of volunteer recruitment, training, and management
}

\begin{abstract}
In this paper we analyze the costs and benefits of the investments that non-profit organizations (NPOs) make for the recruitment, training, and management of volunteers. Our main research question is whether we can apply the Social Return on Investment (SROI) to the identification and quantification of social returns in monetary terms. We believe that the "SROI of volunteering" may represent an effective instrument of internal control for NPOs for improving efficiency and sustainability. In order to verify the feasibility and appropriateness of the SROI approach, we present a case study on the Italian association Dynamo Camp, which works with children with serious illness through the organization of summer camps that offer "recreational therapy". We believe that the presented methodology has the potential to contribute to the debate about the socio-economic impact organizations create for volunteers and for society at large.
\end{abstract}

Key words: Volunteering; SROI; Non-profit organizations; Dynamo Camp; Social returns. 


\section{Introduction}

Increasingly, non-profit organizations (NPOs) rely on volunteer work for the performance of important tasks. This reduces their human resources costs by cutting salary expenses, but it also requires that some resources are spent for the recruitment, training, and management of volunteers. This is especially true in a context where NPOs, while trying to reduce their costs, are making an effort to increase their levels of professionalization and overall efficiency.

The investment made by NPOs on volunteering is often overlooked because of the gratuity of the service provided by volunteers. However, a careful analysis of this investment and its social returns would be highly beneficial for at least two reasons. First of all, it would shed light on a number of positive externalities and social values created by the organizations when investing in volunteer work. In fact, by investing in volunteering, NPOs create value not only for themselves and the users of their services, but also for the volunteers and for society at large. We believe that a fair representation of the social returns of "volunteer investment" is necessary to correctly report to the stakeholders the "real" value of third sector organizations. Secondly, an analysis of the costs and benefits associated with volunteer investments may also contribute to improving the organization's efficiency and sustainability, as it would shed light on any possible inefficiencies and show room for improvement in actual management practices.

In this context, our aim is to develop a methodology to capture and highlight the broad socio-economic value that NPOs produce through their volunteer recruitment, training, and management activities. We focus, in particular, on the value created by the organization for the volunteers, which is an aspect that is particularly interesting but rarely considered in the literature. The exploratory research question is whether, when considering volunteer recruitment, training, and management activities as a proper investment, the application of the 
Social Return on Investment (SROI) methodology (and therefore the quantification of such social returns in monetary terms) can represent an effective instrument of internal control for NPOs in order to better monitor the costs and benefits of volunteer investments.

In this paper we will discuss an early attempt to operationalize this approach and to apply the "SROI of volunteering" to an Italian NPO (the Dynamo Camp Association) that is characterized by high and diversified investments in volunteering-related activities. We focus on the phases of analysis and valuation of inputs invested, and of mapping and assessing various outcomes. These constitute the fundamental basis for subsequent steps of monetary valuation of outcomes and calculation of the SROI Index the results of which are presented in section 4 .

\section{Theoretical framework}

Volunteering is a complex phenomenon that presents problems for its definition and above all for its measurement in financial or nonfinancial terms (Cnaan et al., 1996). Volunteers represent a large part of the workforce in most voluntary associations and the phenomenon of volunteering is becoming more and more important for organizations and societies (Kreutzer \& Jager, 2011). Motivated by a sense of personal, cultural, religious, or other obligation, volunteers practice a form of work characterized by no monetary compensation that produces tangible and intangible benefits not only for the final users of services, but also for themselves and for society at large.

The measurement and representation of volunteer work as an input and output of an organization's activities is interesting, as it provides an opportunity to improve volunteer efforts, better representing NPOs' economic and social impact (ILO, 2011). This can attract new or old funders who can better evaluate the impact of volunteers on an organization's activities (Connolly \& Dhanani, 2009), thus stimulating their propensity to donate. 
However, according to Salamon et al. (2011), the evaluation and measurement of the economic value of volunteer work is characterized by many significant conceptual and methodological challenges:

1. the definition of volunteering is unsettled because the very term carries different meanings and different connotations in different cultures and contexts (Ilo, 2011);

2. the focus of volunteer work measurement is often on the level of inputs (work time) used for providing the related service or on the combination between the inputs used in realizing services for the users and the outputs obtained. The problem here is that in the case of volunteering, a wide range of outputs can result and these outputs can belong to the volunteers or to the users or society in general.

3. In the literature there is no general agreement on a singular valuation method to determine the monetary value of inputs or outputs of volunteering. This is because there is no market-determined price that can stand automatically as the value of volunteer work. The most recommended and used substitute for the price of volunteer work is the wage of a paid worker doing a similar job that the volunteer does for free (the so called "replacement cost approach"). A possible alternative method, the "opportunity cost approach," consists in determining the value of the time that the volunteers could spend in their regular job if they were not engaged in volunteering. On the output side, the volunteer's share of the output and many of the outputs produced by them are also difficult to evaluate, since they are often not subject to market forces. Two approaches for identifying possible proxies of non-market goods or services can be discerned. The first one is linked with the concept of "observed market proxies." In this case the evaluator essentially identifies an analogous market service or good that can act as a substitute. A second possible approach for estimating the value of non-market goods or services is known as "contingent valuation," which 
means asking those making use of a non-market good or service directly to put a monetary value on perceived benefits for goods or services received for free. In this sense it is possible to ask users (as an output measure) or volunteers (as an input measure) to indicate the worth of the service through a sort of survey process (Adamowics et al., 1998, Arrow et al., 1993; Carson et al., 2001; Goldschmidt, 1993, Mook et al., 2005; Portney, 1994; Quarter et al., 2003).

4. Care must be taken in identifying the unit of analysis (at an individual, organizational, or economy-wide level) depending on the evaluation approach that has been adopted by the evaluator.

In short, it is possible to affirm that NPOs resist calculating volunteers' value due to methodological problems, valuation costs, and/or a desire to not overestimate the revenues of the organization (Mook et al., 2005).

Pendlebury et al. (1994) suggest that unreliable assessments of volunteers' inputs (time donated) and outputs (benefit generated for the organization and for volunteers) for which there is commonly no market value are the most significant reason for misreporting on volunteers' value in the third sector organizations. The collection of data on volunteer work can also be costly for NPOs with already limited financial resources (Mook et al., 2005; Cordery et al., 2013). Trigg and Nabangi (1995) confirm that one more reason NPOs ignore volunteer contributions in their annual reports is that they want to "look poor" in the eyes of the stakeholders, thus highlighting the organization's need for donations.

Many scholars (Gaskin, 2000, 2004; Independent Sector \& UN Volunteers, 2001; Mook \& Quarter, 2006; Mook et al., 2003; Mook et al., 2005) have tried to propose diverse social accounting approaches for facilitating volunteer work measurement and representation in NPOs' reporting, and this is one of the main strand of studies (in terms of published 
articles) in the literature on accounting for third sector organizations on volunteering evaluation.

An interesting new strand of research is linked with the fact that, although volunteer work is free for the entities which take advantage of this service, it has implicit costs for NPOs in terms of volunteers' recruitment, training, and employment (Graff, 2006; Grantmaker Forum on Community and National Service, 2003; Mook et al., 2005).

The implications of these costs significantly affect NPOs' accounting and reporting practices and limit the growth of volunteer work itself (Sajardo and Serra, 2011). Attribution of costs for volunteer recruitment, training, and management can be difficult to assess without a system of cost accounting that aims at computing the costs of volunteer work in a scientific manner, although recent software technology may contribute in finding a solution to this type of problem (Cordery et al., 2013). Furthermore, using volunteers can also pose problems, such as conflict with trade unions, liability issues for refunding volunteer activities, or worries from employees that volunteers may replace them.

In the literature there is evidence that organizations choose to use fewer volunteers as the cost of volunteers increase (Emanuele, 1996; Handy and Srinivasan, 2005); nevertheless, many NPOs recognize that they cannot provide their services and conduct their activities without volunteer contributions (Cordery and Tan, 2010), and many organizations would be willing to use volunteer work even if the costs of volunteer labour and connected benefits made it irrational to do so in a purely monetary sense. Indeed, the use of volunteers in NPOs depends not only on the relative cost and productivity of volunteer work compared to paid labour, but also on the indirect benefits that can result from volunteer involvement (Handy and Brudney, 2007).

According to Handy and Srinivasan (2004) volunteers can contribute in improving many aspects of an organization's management: the reduction of labour costs, the organization's 
capability of providing services, the support of donors, the attractiveness of NPOs as workplaces, the users' satisfaction (Hotchkiss et al., 2009), the connection with the local community, and the relevance of the organization to its stakeholders (Narraway and Cordery, 2009). In short, the measurement of inputs, outputs, and possible outcomes of volunteer work can provide useful information and data for organizations in terms of the costs of recruitment, training, and management (Adams et al., 1989; Hotchkiss et al., 2009), as well as on the benefits that volunteers, local communities, users, and organizations can obtain from this experience (Hager and Brudney, 2004).

We need to consider a wide array of social impacts: on the volunteers themselves, the beneficiaries of their activities, the organizations they operate in, and, more generally, the quality of life of the societies involved (Day and Devlin, 1998; Howlett, 2011, Rochester et al., 2009, Lyons et al., 1998; Salamon et al., 2011). Obviously, assessing these aspects in a quantitative manner presents some crucial difficulties related to the evident subjectivity of the issues. Indeed, it has also been stated that "economic weight may constitute one of the easier facets of volunteering's impact to measure. If not the endpoint in measuring the contribution of volunteering, therefore, economic impact is certainly a convenient and useful starting point" (Salamon et al., 2011, p. 221).

An attempt to apply a cost-benefit analysis to volunteer work has been recently made by Handy and Mook (2011). They base their assumptions on the literature and on the socalled "Volunteer Investment and Value Audit" (VIVA) model, developed during the 1990s in the United Kingdom. The VIVA model foresees that "for every pound invested in volunteers, there is a return of X pounds in the value of the volunteers' work" (Gaskin, 1999, p. 36).

According to Handy and Mook (2011) and the previous literature on this topic (see, for example, Handy et al., 2006), the main benefits of volunteer work are: 
- the so-called "warm glow" from the very act of giving;

- increasing an individual's social capital (Andreoni, 1990; Cnaan and Goldberg-Glen, 1991; Glaeser et al., 2002; Freeman, 1997; Govekar and Govekar, 2002; Prouteau and Wolff, 2007; Wilson and Musik, 1999);

- psychological and physical health improvements, especially among older volunteers (Greenfield and Marks, 2004; Li and Ferraro, 2006; Musick and Wilson, 2008; Thoits and Hewitt, 2001);

- skills/training to enhance human capital, curriculum vitae, salary, career prospects and reentry into the labour market (Hackl et al., 2007; Handy and Greenspan, 2009; Musick and Wilson, 2008).

Of course, the kind of benefit depends on the type of volunteers, since those involved in board governance of NPOs are surely different from those engaged in directly providing human services (Handy and Mook, 2011).

In this study, we aim to study whether it is possible to identify and measure the social returns of investments made by NPOs when they recruit, train, and employ volunteer human resources using SROI analysis.

SROI analysis evolved towards the end of the 1990s out of traditional cost-benefit analysis through the work of the Roberts Enterprise Development Fund (REDF) in San Francisco (Emerson et al., 2000; Olsen and Lingane, 2003). It was later modified and amplified by the same organization. Another variation of SROI analysis was proposed by the New Economics Foundation (NEF, 2004 and 2009) in London and applied to a set of social enterprises in the UK.

Over the past few years many NPOs and corporations have adopted SROI analysis to measure their socio-economic impact.

Some well-known cases and "best practices" are the following: 
- social enterprises in San Francisco that have been following the REDF approach to SROI analysis since 1997;

- the Scottish Charity Wise Group, which offers job and training opportunities for people in the local community;

- and the multinational Dutch electronics corporation Philips.

Furthermore, In the UK, the government and policy makers have actively encouraged SEs to measure their socio-economic impact using SROI (Nicholls, 2007), while also establishing, starting in 2007, an investment fund for sustaining new social enterprises (Alcock et al., 2012). Currently, SROI has become a global product, adopted in many countries worldwide, producing interesting experiences in both Europe and Asia (SROI network, 2011).

The main aim of SROI is to measure economic and social value generated by an organization (profit or non profit) in the local community in order to obtain a rational - though not strictly objective - quantification of impact generated (Manetti, 2012). The logical premise of this analysis consists in the fact that the creation of value goes in three directions: economic, socio-economic, and social (Scholten et al., 2006). The end result of the implementation of SROI analysis is the creation of an indicator that represents the return in socio-economic terms for every monetary unit spent on the project and/or in the organization as a whole (REDF, 2000, 2009).

SROI has been promoted as a way to enable the third sector to better understand the wider impacts of their services and activities, and quantify the total value generated in monetary terms (Millar and Hall, 2012). It is based upon a positivist theory of accounting (through the explicit goal of monetizing the results obtained) and cost-benefit analysis, since it aims at assigning a monetary value to social and economic returns in order to demonstrate wider value creation (Rotheroe et al., 2007). In other words, it indicates the value of the socio-economic benefits created by an organization in relation to the costs sustained in 
achieving institutional goals (Emerson et al., 1996).

In the following sections we apply the SROI model to a particularly significant Italian case with the characteristics of a high incidence of voluntary work, high investment in volunteer training and management, and significant outcomes in terms of socio-economic impact generated from volunteering.

\section{Methodology}

We aim to contribute to the literature by applying the SROI methodology to the evaluation of volunteer work in NPOs in order to act as an instrument of internal control. According to the critical theory of accounting, even if the real impact generated by volunteering is not totally represented, the measurement and representation processes involved in SROI analysis carry out a fundamental function of internal control and, from an organizational point-of-view, is a powerful operating mechanism (Chua, 1986, Power and Laughlin, 1996, Lukes, 1974) highlighting the drivers of performance that can be activated to improve effectiveness and efficiency.

The literature contains many detailed references to the application of SROI analysis for evaluating the socio-economic impact generated by NPOs and social enterprises (Manetti, 2012; Millar and Hall, 2012), but nothing has been done on the impact of volunteer work.

According to the NEF, the SROI process is based on the identification of activities using an input-output-outcome model, gathered through dialogue with stakeholders, in order to avoid:

- self-referential decision processes;

- duplication of measurements for diverse categories of stakeholders;

- incorrect attribution of indicators to certain stakeholders. 
Referring to the overall methodological approach elaborated by the NEF, and adapting it to the specific objective of our research, we elaborated a methodology made up of the following steps:

1. Contextualization of the organization, its mission and activities, and its internal structure;

2. Mapping of all the activities that concern the attraction, selection, recruitment, training, coordination, and supervision of volunteers;

3. Identification and monetary valuation of the inputs used by these activities;

4. Identification of the corresponding outputs;

5. Participatory mapping of the outcomes, with the involvement of relevant stakeholders, and identification of indicators for their participatory quali-quantitative estimation;

6. The identification and calculation of appropriate financial proxies for the economic valuation of the outcomes;

7. The subtraction from the values of potential displacement effects, deadweight effects, attribution issues, and drop-off effects in order to obtain the monetary value of impacts produced.

8. Actual calculation of the SROI Index.

While most investments are easily quantified (they have a clearly identifiable market price), the economic valuation of the outcomes may pose more challenges. For starters, it is important to determine the duration of various outcomes. Some activities have long- or very long-term effects on users (even covering their entire lifespan), while the utility of others is limited to periods shorter than one year. Then the organization must assign a monetary value to the outcome. The considerations expressed by the NEF on the matter refer to two opposing problems - the presence of values that are near to those of the outcome (proxy) and the absence of such values. In the first instance, the market value might not necessarily be the best approximation to a monetary measurement of outcome. 
When no financial proxy is immediately available, one of the following approaches is used:

- contingent valuation, which means asking stakeholders to put a monetary value on perceived benefits;

- revealed preference, where the financial value is derived from that of similar goods or services that have a market price (as long as this is reasonably widespread and competitive);

- travel cost method, which verifies how far the average user is willing to travel (financial proxy is represented by transport costs) to gain access to a particular item or service;

- average household spending, which evaluates family spending habits for activities over and above those necessary to satisfy primary needs (free time, personal wellbeing, hobbies, and sport).

The last step consists of subtracting from the value obtained for the outcomes any potential displacement effects, deadweight effects, attribution issues, and drop-off effects. Once deductions have been made for these effects, impact can be calculated by multiplying the financial proxy of each outcome by its quantity, repeating the operation for all the outcomes found.

Finally, the result of the previous sum (total impact) is corrected by taking into account possible repercussions over the course of several years of the impact of each outcome. To this end, it is necessary to project along a temporal axis the value of impact of each outcome throughout the estimated duration of the effect. To make this calculation easier, it is advisable to limit duration of impact, given the complexity of calculations that would result.

In this study we adopted a case study approach as a means of answering the exploratory research question (Eisenhardt, 1989; Yin, 1994), studying. Case studies have been 
defined in the literature as "research situations where the number of variables of interests far outstrips the number of data points" (Yin, 1994, p. 13) or as "a research strategy which focuses on understanding the dynamics present within single settings" (Eisenhardt, 1989, p. 534). While case studies may use quantitative data, they also seek to study phenomena in their specific contexts (e.g., Pettigrew, 1973; Gibbert et al., 2008). According to the literature, building theory from case studies is a research strategy that involves using one or more cases to create theoretical constructs, propositions and/or midrange theory from case-based, empirical evidence (Eisenhardt, 1991).

In our research we utilize a single case study, the Italian association Dynamo Camp that works in favour of children with serious or chronic illness through the organization of summer camps that offer "recreational therapy". We selected this association for three fundamental reasons:

1. the strong presence of volunteers in terms of contribution to the institutional activities and providing services for the users;

2. an already consolidated practice of measuring and representing volunteer work in the annual report;

3. and the willingness of management, volunteers, and users to collaborate in this research project.

Moreover, we noted that this case ensured high accessibility to data, in terms of archival analysis, management availability to dialogue and interaction, and participatory observation during the camps. These factors were fundamental for an in-depth study of the strengths and weaknesses of our case study's evaluation of volunteer work as a socio-economic investment, as well as to understand which elements might be replicable in other contexts.

We decided upon multiple data collection methods according to the steps of Eisenhardt's process (1989) of case study analysis. Special emphasis was placed on three 
main sources of data and information: archival analysis, participatory observations, and interviews with managers and volunteers. Our methodological approach incorporates both quantitative and qualitative data and begins as close as possible to the ideal of no preconceived theories to test. However, we determined the research question and some variables prior to commencing the research (Siggelkow, 2007).

We carried out the literature review and arranged the initial briefings with Dynamo Camp's staff. During this first phase of exchange, we discussed with Dynamo's management the scope of the research and collected their views on its potential use for improving internal management and external communication of the Association. In this phase, we also gathered relevant archival documents, including the Association's Statute, its annual reports for the years 2011 and 2012, the volunteers' handbook, and various training programs. These helped contextualize the organization's mission and activities, and in the analysis of its internal structure (see step 1 of the SROI as reported at the beginning of this section).

After completion of this phase, we started the analysis of the inputs, outputs, and outcomes of volunteer-related activities of the association. The first step involved the elaboration of a series of possible activities undertaken by the Association in order to recruit, train, and coordinate its volunteer human resources.

With regards to recruitment, our hypothetical list of activities included media campaigns (TV, radio, social networks), campaigns by key testimonials (mainly former volunteers), production of formats and documents to be used in the selection process, and interviews with candidates. Among the training activities, on the other hand, we expected to find organizational courses for volunteers and the production of guidelines and supporting documents. Lastly, in the area of coordination we expected to find activities such as organization of volunteers' roles in the recreational therapy camp, and supervision of their work, support, and evaluation activities. 
These assumptions were formulated throughout the first phase of exchange with Dynamo's staff, and were later verified in an interview with the HR manager in order to produce a more detailed and fully comprehensive list.

Once the mapping was complete, each activity was associated with the corresponding inputs (human resources, material resources, services) employed for its implementation. Again this work was carried out in a participatory way through collaboration with Dynamo's staff working in the relevant areas and in accounting.

In the subsequent steps, we carried out the quantification of the corresponding cost for each input identified. We strove to create a correct attribution of human resources costs and avoid duplication in the measurement of other costs. Thanks to this process we were therefore able to perform a complete and reliable quantification of the investment made by Dynamo Association in order to recruit, train, and coordinate volunteers.

With respect to the mapping and quali-quantitative assessment of the outputs and outcomes, the approach was similar, although we did use questionnaires to gather data from the volunteers. Again, the model we developed aimed to shed light mostly on outcomes of the activities concerning recruitment, training, and employment of volunteers. Therefore, The starting point was the construction of a set of assumptions concerning inputs, outputs, and outcomes.

With respect to recruitment activities, we took into account the possibility that campaigns and advertising could be linked to outcomes, such as increased sensibility towards the mission of Dynamo, the possibility of being engaged in voluntary activities, and a reduced need for wage labour. With reference to the training of volunteers, we assumed that internal and external training and hours of effective activities (learning by doing) could lead to outcomes such as the acquisition of new technical and relational skills and an increased possibility of finding a job for unemployed volunteers or a better job for employed ones. 
Finally, with regards to employment of volunteers during the camps, we expected the main outcomes to be related to personal satisfaction, increase in social relations, attachment to Dynamo Camp's cause, and subsequent willingness to donate or raise funds for Dynamo. These initial ideas were shared and debated with former volunteers ${ }^{1}$ of Dynamo Camp in five preliminary interviews.

The interviews allowed us to discuss with volunteers the different outcomes, identify other issues of interest, and help us define the contents and structure of a questionnaire that we subsequently submitted to 29 volunteers at the Dynamo camp in June 2013. The questionnaire embraced the following areas: overall profile of the volunteer, previous work and volunteer experiences, how did the volunteer get in touch with Dynamo, training received, improvement of technical skills, relational, logistic and organizational skills, networking and social capital, personal satisfaction, costs of volunteering (sustained by the volunteers themselves), contribution in terms of working hours, donations made by the volunteers, and spontaneous fund-raising and promotional activities.

Two researchers personally visited Dynamo Camp sites in June 2013 and administered the questionnaire to various volunteers: 18 volunteers received the questionnaire in person, and 11 additional volunteers that had already left the site were reached by e-mail and returned the questionnaire within one week.

The contemporary use of literature review, archival analysis, participatory observation, interviews, and questionnaires facilitated cross-checking of the data, and therefore contributed to strengthening the constructs (Yin, 2009) and answering the research questions.

Upon completion of data collection, data analysis began at an organization level so that the research team was able to gain a deep familiarity with the single case (Eisenhardt, 1989, Yin,

\footnotetext{
${ }^{1}$ Two of these former volunteers attended more than one camp and are therefore called "expert volunteers" according to Dynamo's language.
} 
2009). In the following sections we present the results of the data analysis and discuss their implications in terms of SROI analysis applied to the "Dynamo Camp" volunteer evaluation

\section{Results}

Dynamo Camp is a non-profit volunteer organization formed in 2006 that performs its activities for the benefit of children and young people suffering from serious and chronic diseases (Berardi 2013). It is the result of a Venture Philanthropy intervention operated by the Foundation Dynamo - a Milan-based participatory Foundation connected to the INTEK group - which was born and developed thanks to the support of several private companies and socially responsible businesses (Berardi, 2013). A new social enterprise called Dynamo Academy was also created in 2010 as part of the Dynamo group, with the aim of ensuring the economic sustainability of the Camp through the supply of paid training courses. Dynamo is part of the SeriousFun Children's Network, an international network founded in 1998 by Paul Newman that operates camps in 17 countries and numerous other international partnership programs.

Dynamo Camp organizes a summer camp located in Limestre near Pistoia (Tuscany,Italy) that hosts free holiday and recreational periods for children with serious and chronic diseases, particularly oncohematological and neurological diseases, rare syndromes, spina bifida, and diabetes. The Camp opened its doors in 2007, welcoming sixty children. Each year since, the number of children, diseases accepted, and programs have increased. It now welcomes more than 1,000 children each year and includes healthy siblings and parents in special sessions as well. It offers programs each month throughout the year, through sessions held in summer, during the Easter and Christmas holiday breaks, and on weekends for families, as well as international sessions. The camp is located on a 900-hectare area and includes a reserve area affiliated with the WWF (Dynamo Oasis). It is possible to identify 
within Dynamo Camp both paid staff members and different categories of volunteers, all of whom work together for the achievement of corporate objectives.

In the following sections we report the results of our data collection and analysis activities, starting from the illustration of the inputs used and costs sustained by Dynamo in the generation of volunteering, and moving on to the monetary evaluation of corresponding outcomes and to the calculation of the SROI index.

\subsection{Inputs of volunteer recruitment, training, and management activities}

The mapping exercise led to the identification of the following activities and corresponding inputs used and costs sustained by the Association Dynamo Camp for the recruitment, training, and management of volunteers.

INSERT TABLE 1 HERE

INSERT TABLE 2 HERE

INSERT TABLE 3 HERE

The mapping of the outcomes was carried out through the administration of a questionnaire for volunteers. The profile of the volunteers and their perceptions about the outcomes of the volunteer experience are reported in the following sections.

\subsection{Profile of the volunteers}


Of 29 volunteers interviewed, 13 were women and 16 were men. The youngest volunteer of the group was 25 years old, while the oldest was 55; overall, the distribution by age was relatively even and just slightly shifted towards the higher end, with a median and average age of 43 and 42 years respectively. Except one housewife, all the other (28) volunteers had a formal and paid job, as employees or professional freelancers.

Over two thirds of volunteers (21 individuals) reported previous experiences of voluntary work, mainly with Caritas, Red Cross, and other volunteer organizations that offer medical and social care for children and people with disabilities. The remaining 8 volunteers did not have any previous experience in volunteering. Among the paid work experiences, 5 volunteers reported that they had worked in the social services sector.

Over half of the volunteers (15 out of 29) had learned about the existence of Dynamo Camp and the possibility to take part to its activities thanks to the promotional radio campaign, while just over one quarter ( 8 volunteers) learned about it through their employer. Only 2 volunteers reported that they had come in contact with the association by word of mouth, and the others through a mix of sources (internet, other organizations, etc.).

Seventeen volunteers were volunteering with Dynamo Camp for the first time, while 12 persons had already taken part in at least one other camp ( 7 had volunteered for Dynamo once before, while 5 had attended more than one Camp as volunteers). Some expert volunteers kept the same role, while others changed roles in order to try different experiences. In some cases (at least two explicitly reported cases) volunteers used their professional skills during the volunteer experience at Dynamo Camp (e.g. one professional driver worked as a driver for the children's bus during the Camp).

All but 2 interviewees attended at least 1 training session organized by Dynamo: 23 people attended a 2-day volunteer session, while 18 volunteers took part in a pre-Camp training session (1 day); some attended both. 
Our questionnaire confirmed the estimates of working hours provided by Berardi (2013): the total number of volunteer hours for each performed activity and required skill can be easily calculated by considering that volunteers who oversee dormitories of children contributed a total of 194 hours during the 9 days of the Camp session; technical volunteers provided a total of 80 hours, supporting camp activities such as bus driving or meal cooking; volunteers who supported activities such as climbing or farming provided around 40 hours of work for each Camp session.

\subsection{Outcomes of volunteering}

The questionnaire allowed us to verify our assumptions and to gather information on the following typologies of outcomes, which we had identified through the initial interviews with Dynamo volunteers and internal staff:

- Improvements in the technical and professional skills of the volunteer;

- Improvements in relational and soft skills;

- Improvements in logistical and organizational skills;

- Broadening and improvement of future employment opportunities;

- Expansion of social networks and social capital;

- Personal satisfaction and well-being;

- Increased willingness to donate and support Dynamo through fund raising activities.

We found that 10 out of 29 volunteers claimed that they had improved their technical and professional skills during Camp activities, particularly in regards to relating to children (13 volunteers answered they had improved their skills in this area "much" or "very much"); 15 volunteers reported to have increased their relational capacities after the experience at Dynamo; 5 and 25 volunteers claimed to have learned how to better manage relations with adults and children, respectively; 9 volunteers reported that they had increased their network 
of friends or acquaintances; 8 volunteers claimed to have much or very much improved their logistical and organizational skills (17 volunteers reported that they had improved their skills in terms of managing their time and other complex activities).

In general, most of the respondents (16 of 29) felt that the new or augmented skills would benefit them both in their personal and professional lives. Among the most important and useful skills, they indicated the ability to manage time, interpersonal relationships, and conflicts.

In terms of the possibility of using these new skills to acquire a new job, the considerations that emerged are quite mixed. Some volunteers emphasized the possibility of using their new skills in their future career, while others, especially those who worked in a different sector, were less willing to consider the experience at Dynamo professionally useful.

In general, the volunteers declared that they would not pay for attending formal training courses that focused on the specific skills they improved upon at Dynamo. Consistently, none of them had ever paid for any equivalent courses in the past. When asked if, on the other hand, they would be willing to acknowledge the formative value of Dynamo Camp through the payment of a participation fee, most of them answered that they would not pay for participating. Some volunteers, meanwhile, did try to attribute an economic value to their experience at Dynamo, estimating it to be around 300 euros.

We further verified whether the volunteers had to bear expenses in order to volunteer at the Camp (we considered this an additional measure of the value they indirectly attribute to the experience). Twenty-six volunteers confirmed that some of their indirect participation costs - in particular, travel expenses - had not been refunded. The average expense sustained by the volunteers was 102.80 euros, while the highest reported expense was 270 euros. This data suggests that despite the fact that volunteers do not consider it appropriate to pay directly for becoming Dynamo volunteers, they do accept the need of absorbing some indirect costs. 
Lastly, most volunteers (28 out of 29) reported high or very high levels of personal satisfaction derived from the experience at Dynamo, especially in relation to the activities that directly involve disabled children.

In order to identify the direct monetary benefits the Dynamo Association obtained from the involvement of the volunteers, we asked the latter whether they had made any donations to Dynamo after the experience at the Camp. More than on-third of the volunteers $(38 \%)$ donated $5 \%$ of their personal income $\operatorname{tax}^{2}$ to the Dynamo Association; two of them organized fund raising events in favour of the Association, while some made occasional donations during the year. Others made additional purchases at the social shop of the Camp, and some encouraged their friends and colleagues to volunteer at Dynamo Camp by talking to them in a positive way about their experiences.

\subsection{Calculation of the SROI Index}

Tables 4 and 5 show the SROI impact map (NEF, 2009) and the link between activities, inputs, outputs, outcomes, financial proxies, and monetary value of impacts. All the data refer to the fiscal year 2012 .

INSERT TABLE 4 HERE

Concerning the recruitment activities, we identified the following relevant outputs:

a) promotional and awareness raising campaigns in different media;

b) interviews for the volunteer selection process.

For moving from outputs to outcomes it is necessary to focus on the relevant change produced by these outputs that relevant for stakeholders. Taking into account data obtained from the

\footnotetext{
${ }^{2}$ Italian law allows individuals to donate $5 \%$ of their income-tax to a NPO.
} 
questionnaire described in section 4.2, and considering that our assessment focuses on volunteers, a single category of stakeholders was included (volunteers) and a single outcome was evaluated (more information and awareness). We argue that, through Dynamo's promotional activities, volunteers became more informed about Dynamo activities and the children's conditions. We decided to consider outcomes just for volunteers because we are assessing the return on investment on them and, thus, we included just the cost of inputs referred to the recruitment, training, and employment of these subjects.

With regard to the training of volunteers, the most relevant outputs identified are:

a) the hours of training for each volunteer;

b) the volunteers' handbook .

The change produced by these outputs on volunteers include learning new skills or improving existing ones, and increasing future employment opportunities.

Lastly, concerning the outputs related to the employment of volunteers, we considered:

a) the contribution of volunteers to the realization of 10 camps;

b) the contribution of volunteers to the realization of 7 family weekends.

Two related outcomes have been defined after having analyzed the results of the questionnaire administered to volunteers.

Since volunteers often felt better and more inspired, gaining a sense of self-realization through Dynamo activities, an increased personal satisfaction and wellbeing was set as a first outcome. Secondly, volunteers reported that Dynamo activities helped them make new acquaintances and gain satisfaction in improving their social network; thus, we defined as a second relevant outcome the opportunity of social networking and increase in social relations.

The next step was to find suitable financial proxies that could efficiently measure the impact on volunteers linked to the outcomes shown in Table 4 and described above. 


\section{INSERT TABLE 5 HERE}

The participation cost of an introductory workshop on severe diseases of children and recreational therapies was used to estimate the monetary value of increased awareness of volunteers on this topic. These workshops are often provided for free, which is why we preferred to set this value at 0 in order to not overestimate its impact. Participation cost for a professional training course of 30 hours on work organization and security was used to estimate the value of the skills improvement experienced by volunteers and the improvement of their future job opportunities.

Since volunteers claimed to have obtained great satisfaction and a sense of selfrealization from the opportunity to help Dynamo Camp's children, we asked them how much would they pay for a such as positive experience, using this willingness to pay as a financial proxy for their satisfaction.

Moreover, in order to quantify the positive expansion of volunteers' social networks, we adopted the principle of similarity by trying to identify an activity that could have similar effects and use its cost as a shadow cost and financial proxy for this type of outcome. We chose to include the cost of an annual subscription to a local hiking group with three excursions because it is a pleasant activity that enable participants to meet new people outdoors, just as they would at one of the Dynamo camps.

The proxy value per unit was multiplied for the total number of volunteers in 2012 (606). Then some technical step was conducted in order to take into account:

- deadweight (how much of the change would have happened anyway without the measured activity?);

- attribution (if the impact is not entirely attributable to the measured activity, which is the percentage of the impact produced solely by Dynamo Camp?); 
- drop-off (how much does the outcome drop-off in future years?);

- and, duration (how many years does the effect last?).

The value defined for each of these aspects is shown in Table 5. These steps enabled us to calculate the total value of impacts (NEF 2009).

After having applied a discount rate (3\%) to the total value of impacts per year in a five year framework, the Total Present Value of impact was calculated. When making economic estimates and choices based on cost-benefit analyses, the British Treasury Minister's Green Book for public authorities recommends the base rate of $3.5 \%$ (HM Treasury, 2003). However, following criticisms made by the "Stern Review on the Economics of Climate Change" (Stern, 2006), the Treasury lowered the rate to 3\%, due to eliminating the effect of pure time preference (estimated at 0.5\%) (Groom et al., 2005).

We defined the Social Return on Investment on Volunteers as the ratio between "Total Present Value of impacts on volunteers" and the "Total Cost of Inputs required to recruit, train and manage volunteers." In our Dynamo Camp case-study, and after considering the calculation shown in Table 5, the SROI index was calculated at 1.65.

\section{Conclusions}

The result of our case study confirms that investing in volunteering activities leads to a positive impact on volunteers in terms of skills, social relations, and personal satisfaction.

In this paper we explored the possibility of developing a new methodology to analyse the costs and benefits (intended as the socio-economic value created) of the often invisible investments that third sector organizations afford for the recruitment, training, and management of volunteers. Our main research question is whether, after considering volunteer recruitment, training, and management activities as a proper investment, we can apply the Social Return on Investment (SROI) for the identification and quantification of 
social returns in monetary terms. According to the literature (Gaskin, 1999, p. 36; Handy and Mook, 2011), we believe that the "SROI of the volunteer" may actually represent an effective instrument of internal control for NPOs, for better controlling costs and benefits of volunteer investments and improving efficiency and sustainability.

After reviewing the literature on the socio-economic value of volunteering, which served as an introduction to the presentation of our theoretical framework, we discussed the use and logic of the SROI methodology and proposed its adaptation to a NPO case. In order to verify the feasibility and appropriateness of the SROI approach to volunteer-related investments in the non-profit sector, we performed a case study on the Italian association Dynamo Camp. We involved Dynamo's staff in determining the inputs, outputs, and outcomes of all of Dynamo's activities concerning the recruitment, training, and management of volunteers.

A series of hypothesis about the direct and indirect outcomes of these activities, for both the volunteers and the organization as a whole, were verified through the administration of a questionnaire to the 29 volunteers who attended the Dynamo Camp in Limestre in summer 2013.

The results of the questionnaire raised many interesting points about the heterogeneous benefits of the volunteer experience. These benefits ranged from personal satisfaction to improved personal and professional skills, expansion of social relations and networks, and improved future opportunities.

We identified a set of suitable financial proxies for the monetary valuation of these outcomes. Once the change linked to outcomes had been evaluated in monetary terms, we calculated the Social Return on Investment on Volunteers as the ratio between "Total Present Value of impacts on volunteers" and the "Total Cost of Inputs required to recruit, train and manage volunteers". 
Our Dynamo Camp case-study indicates a SROI index of 1.65. This means that 1 euro invested in Dynamo Camp activities about volunteers produce a return of 1.65 euros in terms of information, awareness raising, skills enhancement, greater job opportunity, increased social relations, personal satisfaction and well being for the involved volunteers.

In conclusion, our study suggests that the SROI is an applicable methodology for the identification and measurement of the social returns of volunteer-related investments made by NPOs. However, it is also important to point out that such an application would present some potential points of weakness: it needs to be noted that the quantification of social outcomes and impacts is particularly complex, and may lead to scarcely objective measures, leaving the door open for skepticism among stakeholders.

Even in cases involving an accurate measurement of outcomes, calculating a monetary value remains a very challenging task, as is the identification of possible displacement, deadweight, and drop-off effects. It is also very difficult to avoid mistakes in the attribution of the outcomes to the activities and investments under consideration.

Despite the many challenges and the possibly limited precision of these measures, we believe that the proposed methodology presents many interesting points and has the potential to contribute to the debate about the socio-economic impact that volunteer organizations create for volunteers and for society at large. Moreover, this methodology may contribute to the debate on the efficiency and sustainability of non-profit management. In this respect, future research is needed in order to better define the SROI of the volunteer and to make it a really effective operating mechanism for understanding the internal dynamics of non-profit organizations and for strengthening them in view of the achievement of broader strategic objectives. 


\section{REFERENCES}

Adamowics, W., Boxall, P., \& Louviere, J. (1998). Stated preference approaches for measuring passive use values: choice experiments and contingency valuation. American Journal of Agricultural Economics, 80(1), 64-75.

Adams, J. B., Bossio, R. J., \& Rohan, P. (1989). Accounting for Contributed Services. Norwalk: FASB.

Alcock, P., Millar, R., Hall, K., Lyon, F., Nicholls, A., \& Gabriel M. (2012). Start up and growth: National Evaluation of the Social Enterprise Investment Fund (SEIF). London: Department of Health Policy Research Programme.

Andreoni, J. (1990). Impure altruism and donations to public goods: A theory of warm-glow giving. Economic Journal, 100(401), 464-477.

Arrow, K., Solow, R., Portney, P.R., Leamer, E.E., Radner, R.; \& Schuman, H. (1993). Report of the NOAA Panel on Contingent Valuation.

Berardi, L. (2013). 'Imprenditorialità sociale e gestione dei volontari. Il caso Dynamo Camp', in Colloquio scientifico sull'impresa sociale, 7-8 June 2013, University of Turin.

Cordery, C. J., Proctor-Thomson, S. B., \& Smith, K.A. (2013). Towards communicating the value of volunteers: lessons from the field. Public Money \& Management, 33(1), 47-54.

Carson, R., Flores, N., \& Meade, N.F. (2001). Contingent valuation: controversies and evidence. Environmental and Resource Economics, 19(2), 173-210.

Chua, W. (1986). Radical developments in accounting thought. The Accounting Review, 61(4), 601-632.

Cnaan, R. A., \& Goldberg-Glen, R. S. (1991). Measuring motivation to volunteer in human services. The Journal of Applied Behavioral Science, 27(3), 269-284.

Cnaan, R. A., Handy, F., \& Wadsworth, M. (1996). Defining who is a volunteer: Conceptual and empirical considerations. Nonprofit and Voluntary Sector Quarterly, 25(3), 364-383.

Connolly, C., \& Dhanani, A. (2009). Narrative Reporting by UK Charities. London: Chartered Accountants Educational Trust.

Cordery, C., \& Tan, L. (2010). A survey of the effects of direct financial costs in volunteering. Third Sector Review, 16(1), 105-124.

Day, K.M., \& Devlin, R.A., (1998). The payoff to work without pay: volunteer work as an investment in human capital. Canadian journal of economics, 31(5).

Eisenhardt, K.M. (1989). Building theories from case study research. Academy of Management Review, 14(4), 532-550.

Eisenhardt, K.M. (1991). Better stories and better constructs: the case for rigor and comparative logic. Academy of Management Review, 16(3), 620-627. 
Emanuele, R. (1996). Is there a (downward sloping) demand curve for volunteer labour? Annals of Public and Cooperative Economics, 67(2), 193-208.

Emerson, J., Wachowicz, J., \& Chun, S. (2000). Social Return On Investment: Exploring Aspects of Value Creation in the Nonprofit Sector. San Francisco: REDF.

Emerson, J., \& Twersky, F. (1996). New Social Entrepreneurs: The Success, Challenge and Lessons of Non-profit Enterprise Creation. San Francisco: The Roberts Foundation.

Freeman, R. B. (1997). Working for nothing: The supply of volunteer labor. Journal of Labor Economics, 15(1), S140-S166.

Gaskin, K. (1999). Valuing Volunteers in Europe: A Comparative Study of the Volunteer Investment and Value Audit. Voluntary Action, 2(1), 33-49.

Gaskin, K. (2000). An evaluation of the application of the volunteer investment and value audit (VIVA) in three European countries. London: Institute for Volunteering Research.

Gaskin, K. (2004). Valuing volunteers in Europe. A comparative study of volunteer investment and value audit. London: Institute for Volunteering Research.

Gibbert, M., Ruigrok, W., \& Wicki, B. (2008). What passes as a rigorous case study? Strategic Management Journal, 29(13), 1465-1474.

Glaeser, E. L., Laibson, D., \& Sacerdote, B. (2002). An economic approach to social capital. Economic Journal, 112(483), F437-F458.

Goldschmidt-Clermont, L. (1993). Monetary valuation of non-market productive time methodological considerations. Review of Income and Wealth, 39(4), 419-433.

Govekar, P. L., \& Govekar, M. A. (2002). Using economic theory and research to better understand volunteer behavior. Nonprofit Management and Leadership, 13(1), 33-48.

Graff, L. (2006). Declining profit margin: When volunteers cost more that they return. International Journal of Volunteer Administration, 24(1), 24-32.

Grantmaker Forum on Community and National Service (2003). The cost of volunteers. Denver, CO: Author (Now known as PACE [Philanthropy for Active Civic Engagement]).

Greenfield, E. A., \& Marks, N. F. (2004). Formal volunteering as a protective factor for older adults' psychological well-being. Journals of Gerontology - Series B Psychological Sciences and Social Sciences, 59(5), S258-S264.

Groom, B., Hepburn, C., Koundouri, P. \& Pearce, D. (2005). Declining discount rates: The short and the long of it. Environmental and resource Economics, 32(4), 445-493.

Hackl, F., Halla, M., \& Pruckner, G. J. (2007). Volunteering and income - the fallacy of the good samaritan? Kyklos, 60(1), 77-104.

Hager, M. A., \& Brudney, J. L. (2004). Balancing Act: The Challenges and Benefits of Volunteers. Washington, D.C.: Urban Institute. 
Handy, F., \& Srinivasan, N. (2004). Valuing volunteers: an economic evaluation of the net benefits of hospital volunteers. Nonprofit and Voluntary Sector Quarterly, 33, 28-54.

Handy, F., \& Brudney, J. (2007). When to use volunteer labor resources? An organizational analysis for nonprofit management. Vrijwillige Inzet Onderzocht, 4, 91-100.

Handy, F., Greenspan, I. (2009). Immigrant volunteering: A stepping stone to integration? Nonprofit and Voluntary Sector Quarterly, 38(6), 956-982.

Handy, F., \& Mook, L. (2011). Volunteering and volunteers: Benefit-cost analyses. Research on Social Work Practice, 21(4), 412-420.

Handy, F., Srinivasan, N. (2005). The demand for volunteer labor: A study of hospital volunteers. Nonprofit and Voluntary Sector Quarterly, 34(4), 491-509.

Handy, F., Mook, L., \& Quarter, J. (2006). Organizational perspectives on the value of volunteer labour. Australian Journal of Volunteering, 11, 28-37.

HM Treasury (2003). The green book. Appraisal and evaluation in Central Government. London: HM Treasury.

Hotchkiss, R. B., Fottler, M. D., \& Unruh, L. (2009). Valuing volunteers: the impact of volunteerism on hospital performance. Healthcare Management Review, 34, 2, 119-128.

Howlett, S. (2011). Volunteering and society in the 21 st century, paper presented at the $21 s t$ IAVE World Volunteer Conference, Singapore, January 24-27.

ILO (2011). Manual on the Measurement of Volunteer Work, Geneva.

Independent Sector and UN Volunteers (2001). Measuring volunteering: A practical toolkit. Washington, DC: Author.

Kreutzer, K., \& Jager, U., (2011). Volunteering versus managerialism: conflict over organizational identity in voluntary associations. Nonprofit and Voluntary Sector Quarterly, 40(4), 634-661.

Li, Y., \& Ferraro, K. F. (2006). Volunteering in middle and later life: Is health a benefit, barrier or both? Social Forces, 85(1), 497-519.

Lukes, S. (1974). Power: A radical view, London: MacMillan.

Lyons, M., Wijkstrom, P., \& Clary, G. (1998). Comparative studies of volunteering: what is being studied? Voluntary Action, 1(1), 45-54.

Manetti, G. (2012). The role of blended value accounting in the evaluation of socio-economic impact of social enterprises. Voluntas, First online, 1-22, DOI 10.1007/s11266-012-9346-1.

Millar, R., Hall, K. (2012). Social Return on Investment (SROI) and Performance Measurement. Public Management Review, First online, DOI: 10.1080/14719037.2012.698857. 
Mook, L., Richmond, B.J., \& Quarter, J., (2003). Integrated social accounting for nonprofits: a case from Canada. Voluntas, 14, 3.

Mook, L., Sousa, J., Elgie, S., \& Quarter, J. (2005). Accounting for the value of volunteer contributions. Nonprofit management \& Leadership, 15, 4.

Mook, L., Quarter, J. (2006). Accounting for the social economy: The socioeconomic impact statement. Annals of Public and Cooperative Economics, 77, 2, 247-269.

Musick, M. A., \& Wilson, J. (2008). Volunteers: A Social Profile. Bloomington IN, USA: Indiana University Press.

Narraway, G., \& Cordery, C. (2009). Volunteers: valuable but invisible to accountants? Third Sector Review, 15, 1, 11-29.

New Economics Foundation (NEF) (2004), Social Return on Investment: Valuing What Matters. London: New Economics Foundation.

New Economics Foundation (NEF), \& Cabinet Office (2009). A Guide to Social Return on Investment. London: Society Media.

Nicholls, J. (2007). Why Measuring and Communicating Social Value can help Social Enterprise become More Competitive. London: Cabinet Office.

Olsen, S., \& Lingane, A. (2003). Social return on investment: Standard guidelines. Berkeley CA: University of California.

Pendlebury, M., Jones, R., \& Karbhari, Y. (1994). Developments in the accountability and financial reporting practices of executive agencies. Financial Accountability \& Management, $10,1,33-46$.

Pettigrew, A.M. (1973). The Politics of Organizational Decision-making. London: Travistock Publications Limited.

Portney, P.A. (1994). The contingent valuation debate: why economists should care? Journal of Economic Perspectives, 8(4), 3-17.

Power, M., \& Laughlin, R. (1996). Habermas, law and accounting. Accounting, Organizations and Society, 21(5), 441-465.

Prouteau, L., \& Wolff, F. (2007). La participation associative et le bénévolat des seniors. Retraite Et. Retraite et Société, ${ }^{\circ} 50$.

Quarter, J., Mook, L., \& Richmond, B.J. (2007). What Counts: Social Accounting for Nonprofits and Cooperatives (2nd Ed.). Upper Saddle River, New Jersey: Prentice Hall.

Roberts Enterprise Development Fund (REDF) (2000). SROI methodology. San Francisco: REDF.

Roberts Enterprise Development Fund (REDF) (2009). SROI Act II: a call to action for next generation SROI. San Francisco CA: REDF. 
Rochester, C., Ellis Paine, A., \& Howlett, S. (2009). Volunteering and Society in the 21st Century. Hampshire, England: Palgrave Macmillan.

Rotheroe, N., \& Richards, A. (2007). Social return on investment and social enterprise: Transparent accountability for sustainable development. Social Enterprise Journal, 3(1), 3148.

Sajardo, A., \& Serra, I. (2011). The economic value of volunteer work: methodological analysis and application to Spain. Nonprofit and Voluntary Sector Quarterly, 40(5), 873-895.

Salamon, L.M., Sokolowoski, S.W., \& Haddock, M.A. (2011). Measuring the economic value of volunteer work globally: concepts, estimates, and a roadmap to the future. Annals of Public and Cooperative Economics, 82(3).

Scholten, P., Nicholls, J., Olsen, S., \& Galimidi, B. (2006). SROI. A Guide to Social Return on Investment. Amstelveen: Lenthe Publishers.

Siggelkow, N. (2007). Persuasion with case studies. Academy of Management Journal, 50(1), 20-24.

SROI Network (2011). Guide du retour social sur investissement (SROI). (Les Cahiers del'Institut de l'Innovation et de l'Entre).

Stern, N. (2006). Stern Review on The Economics of Climate Change. London: HM Treasury.

Thoits, P. A., \& Hewitt, L. N. (2001). Volunteer work and well-being. Journal of Health and Social Behavior, 42(2), 115-131.

Trigg, R., Nabangi, F. K. (1995). Representation of the financial position of not-for-profit organizations: the Habitat for Humanity situation. Financial Accountability and Management, 11(3), 259-269.

Wilson, J., Musick, M. (1999). The effects of volunteering on the volunteer. Law and Contemporary Problems, 62(4), 141-168.

Yin, R.K. (1994). Case Study Research: Design and Methods (2nd Ed.). Thousand Oaks: Sage Publications.

Yin, R.K. (2009). Case Study Research: Design and Methods (4th Ed.). California: Sage Publications. 
Table 1 - Activities and inputs used for the recruitment of volunteers

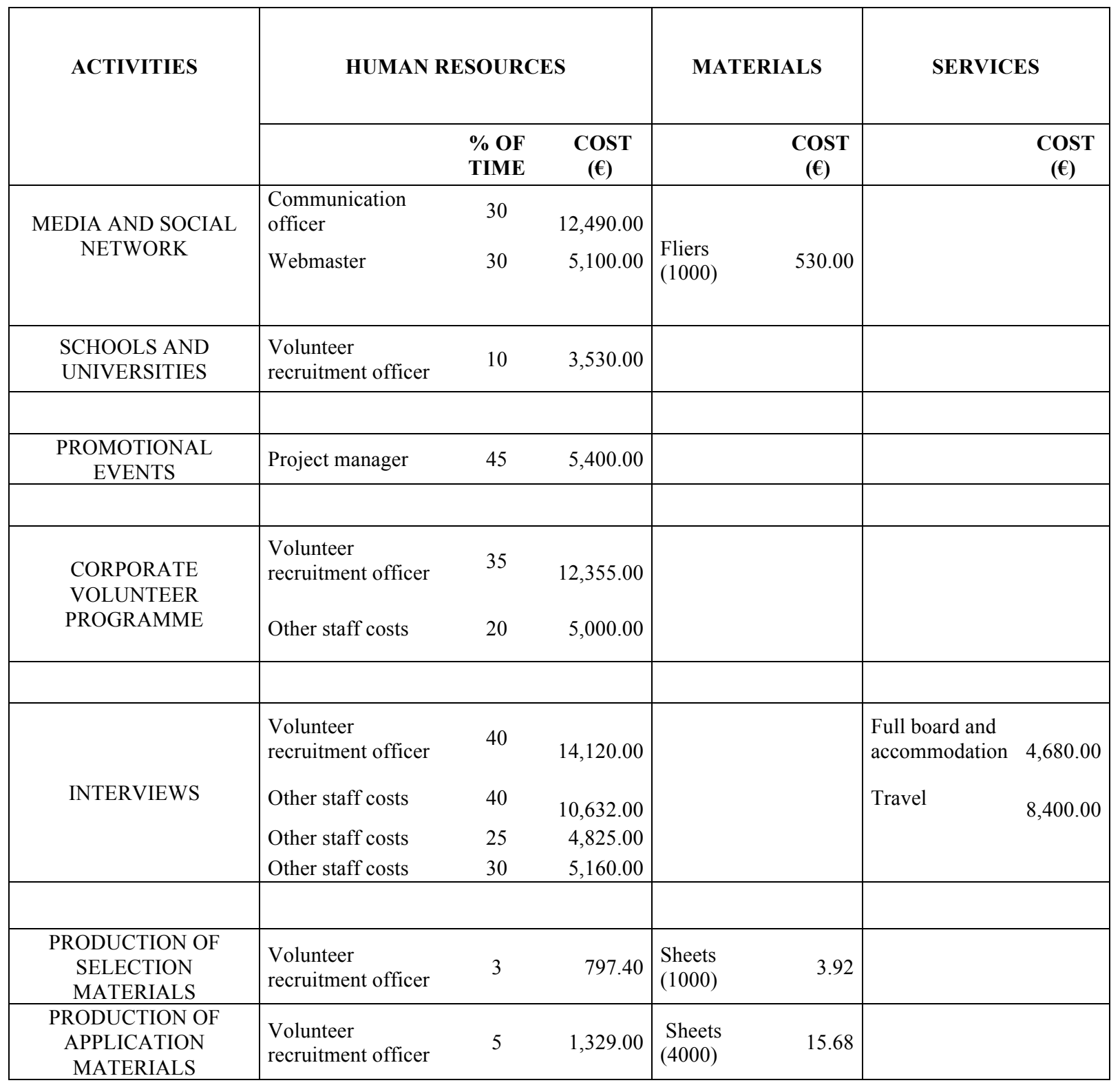

Source: Our elaboration is based on data provided by Dynamo Camp 
Table 2 - Activities and inputs used for the training of volunteers

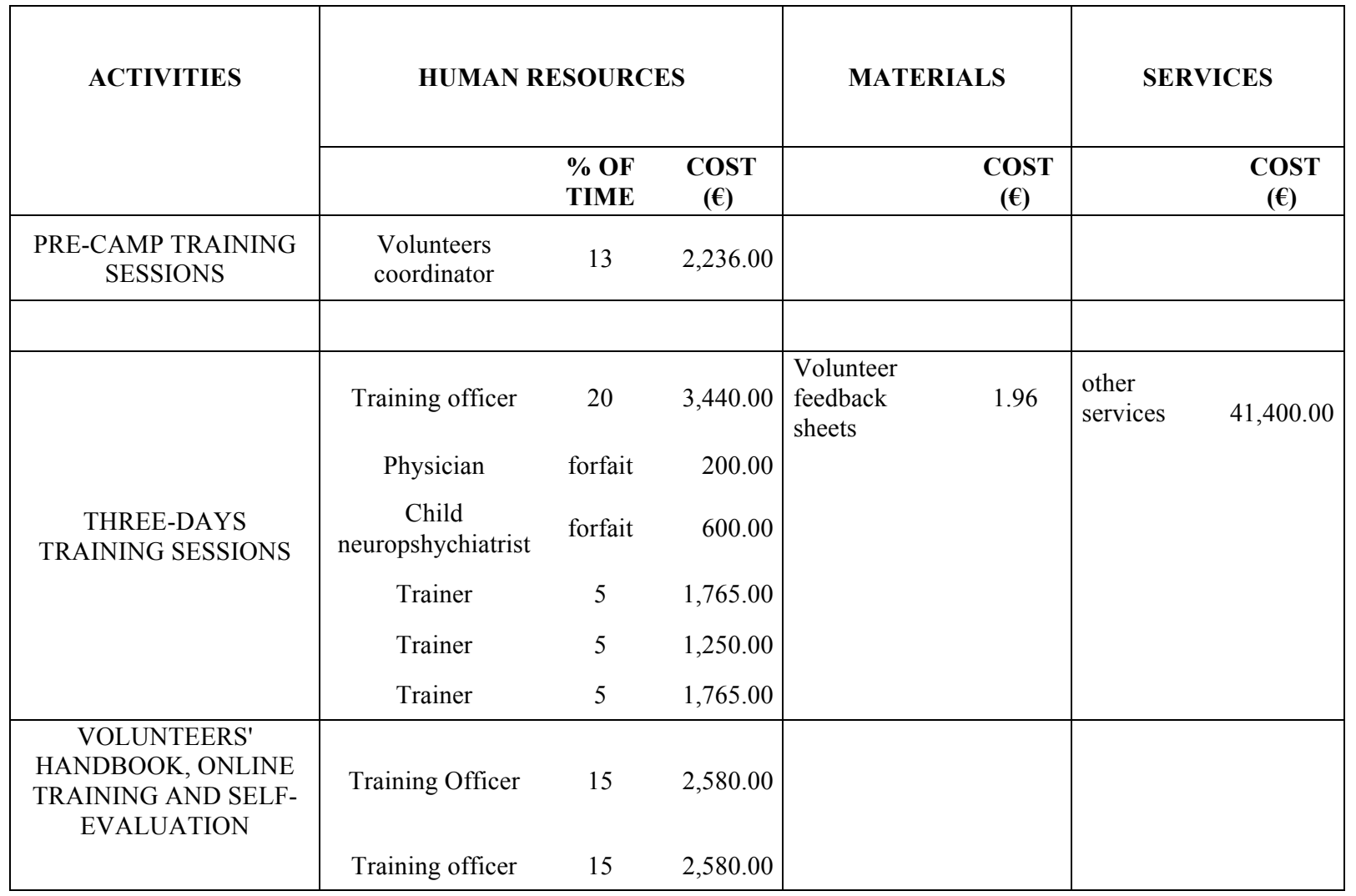

Source: Our elaboration is based on data provided by Dynamo Camp

Table 3 - Activities and inputs used for the use of volunteers

\begin{tabular}{|c|c|c|c|c|c|c|}
\hline \multirow[t]{2}{*}{ ACTIVITIES } & \multicolumn{5}{|c|}{ HUMAN RESOURCES } & \multirow{2}{*}{$\begin{array}{c}\text { MATERIALS } \\
\begin{array}{c}\text { COST } \\
(€)\end{array}\end{array}$} \\
\hline & N. DAYS & $\begin{array}{c}\text { VOLUNTEERS' } \\
\text { COORDINATO } \\
\text { R }\end{array}$ & $\begin{array}{c}\text { VOLUNTEER } \\
\text { S }\end{array}$ & $\begin{array}{c}\text { DAILY FULL } \\
\text { BOARD AND } \\
\text { ACCOMODATIO } \\
\mathbf{N} \\
\end{array}$ & $\operatorname{Cost}(€)$ & \\
\hline SESSIONS & 11 & 1 & 45 & 69 & $\begin{array}{c}314,226.0 \\
0\end{array}$ & \\
\hline $\begin{array}{c}\text { FULL } \\
\text { WEEKEND }\end{array}$ & $4 \quad 4$ & 1 & 35 & 69 & $39,744.00$ & \\
\hline $\begin{array}{l}\text { VOLUNTEE } \\
\text { R } \\
\text { MATERIALS }\end{array}$ & & & & & & $\begin{array}{l}\text { T- } \\
\text { shirt, } \\
\text { badge, } 17,556.00 \\
\text { etc. }\end{array}$ \\
\hline
\end{tabular}

Source: Our elaboration is based on data provided by Dynamo Camp 